\title{
Cegueira, Acessibilidade e Inclusão: Apontamentos de uma Trajetória
}

\author{
Joana Belarmino de Souza \\ Universidade Federal da Paraíba, PB. Brasil.
}

\begin{abstract}
Resumo: $\mathrm{O}$ artigo explora o tema da acessibilidade e da inclusão na era tecnológica, a partir de um inventário das minhas próprias vivências, tendo nascido cega, e, por obra da necessidade da educação especial, tendo sido alfabetizada através do método braile, depois enveredar na era tecnológica, onde se revelou, ora como campo de pesquisa, ora como seara para a militância, o tema da acessibilidade e da inclusão. Parto de uma premissa subjetiva já explorada anteriormente, a de pensar a cegueira como um lugar de onde posso olhar o mundo, avanço, porém, para a outra face da mesma: como o mundo tem olhado para a cegueira? Conclui-se apresentando um cenário ao mesmo tempo promissor e paradoxal para a acessibilidade e a inclusão. Pessoas cegas conquistaram a ciberesfera, desempenham-se bem na web, entretanto, barreiras de acessibilidade são forjadas todos os dias nos ambientes virtuais, o que impacta diretamente nas vidas laborais e socioculturais desses indivíduos. Persiste, na contemporaneidade, espécies de conjuntos de comportamentos cristalizados na cultura, os quais atravessaram toda a história da cegueira, e que podem ser configurados como o fenômeno da invisibilidade em múltiplos processos socioeconômicos e culturais.
\end{abstract}

Palavras-chave: Cegueira, Tecnologia, Acessibilidade, Inclusão, Jornalismo.

\section{Blindness, Accessibility and Inclusion: A Trajectory}

\begin{abstract}
Based on an inventory of my own experiences, this paper explores the theme of accessibility and inclusion in the technological era. I was born blind, was educated using the Braille method because of the need for special education, and then embarked on the technological era, where the theme of accessibility and inclusion was revealed in both the research and the militancy fields. I start from a subjective premise already explored: to think of blindness as a place from which I can look at the world, but I go through to another side: How has the world looked at blindness? The conclusion presents a both promising and paradoxical scenario for accessibility and inclusion. Blind people have conquered the cybersphere, performing well on the web; however, accessibility barriers are forged every day in virtual environments, which directly impacts on the work and sociocultural lives of these individuals. A set of behaviors crystallized in the culture persists in the contemporaneity. These behaviors have gone through the whole history of blindness and can be configured as the phenomenon of invisibility in multiple socioeconomic and cultural processes.
\end{abstract}

Keywords: Blindness, Technology, Accessibility, Inclusion, Journalism. 


\title{
Ceguera, Accesibilidad e Inclusión: Una Trayectoria
}

\begin{abstract}
Resumen: El artículo explora el tema de la accesibilidad y la inclusión en la era tecnológica, a partir de un inventario de mis propias vivencias, habiendo nacido ciega, y, por obra de la necesidad de la educación especial, ser alfabetizada a través del método braille, después emprender en la era tecnológica, donde se reveló, ora como campo de investigación, ya como una mina para la militancia, el tema de la accesibilidad y de la inclusión. Parto de una premisa subjetiva ya explotada anteriormente, la de pensar la ceguera como un lugar de donde puedo mirar el mundo, avanzo, pues, hacia la otra cara de la misma: ¿cómo el mundo ha mirado hacia la ceguera? Se concluye presentando un escenario al mismo tiempo prometedor y paradójico para la accesibilidad y la inclusión. Las personas ciegas conquistaron la ciberesfera, se desempeñan bien en la web, sin embargo, las barreras de accesibilidad son forjadas todos los días en los ambientes virtuales, lo que impacta directamente en las vidas laborales y socioculturales de esos individuos. Persiste, en la contemporaneidad, unas especies de conjuntos de comportamientos cristalizados en la cultura, los cuales atravesaron toda la historia de la ceguera, y que pueden ser configurados como el fenómeno de la invisibilidad en múltiples procesos socioeconómicos y culturales.
\end{abstract}

Palabras clave: Ceguera, Tecnología, Accesibilidad, Inclusión, Periodismo.

\section{Quando se olha para o mundo com o corpo todo}

A primeira memória mais forte da minha infância aconteceu nos meus quatro anos. Me lembro de uma manhã cheia de sol, insetos zumbindo nas flores, pássaros cantando alegremente nas árvores. No quintal de casa, inventei de brincar de ver.

Eu ainda não sabia direito o que era ser cega, senão por ter experimentado no meu próprio corpo de menina, retraimentos, tensões, senão por criar, todos os dias, espaços seguros onde eu pudesse correr, rodopiar, experimentar a força do vento e dos borrifos de chuva no meu próprio rosto, investigar a dureza das pedras e a sensação da terra a escorrer, por entre as minhas mãos.

A cegueira, de fato, não é somente uma condição do nascimento, se quisermos, uma imposição da genética e da biologia. A cegueira, sobretudo, é uma construção sociocultural, amalgamada em proibições, interdições, estabelecimento de limites. Mais que isso, a cegueira é uma construção narrativa, urdida inicialmente no seio da família, para ir se alastrando pelos diversos polos de convívio: a escola, a rua, a comunidade.

$\mathrm{Na}$ minha casa, na zona rural do interior de Pernambuco, convivendo com uma família grande, minha cegueira, pelo menos nos primeiros anos, estava cercada por alguma liberdade. Brincar no pátio grande da casa, subir em pedras e até em arbustos espinhentos, correr e rodopiar com o vento, inventar cercados feitos de madeira e pedra, eram as nossas brincadeiras infantis. A cegueira, parece, estava incorporada àquela economia de ações, àquela largueza de gestos, ao pouco que se falava sobre o fato, senão com as palavras exatas do interior: "Ela é cega", é cega e pronto. Não havia mais nada a ser dito. Os dias estendiam-se como grandes panos lavados, as horas como que se desenrolavam, para o puro experimento de ser.

Naquela manhã pois, o cardápio inventado era brincar de ver. Eu pulava diante de uma fileira de pedras, no quintal de casa e experimentava na minha face a presença das pedras. Ver, para mim, resumia-se à surpresa de sentir as pedras na face, sem tocar nelas. O desfecho veio rápido, interrompendo a brincadeira de ver. O tempo me mostrou que aquele jeito de ver não passava de um modo particular de enxergar as coisas à volta por uma pessoa cega (Sousa, 2000).

Para além da experiência da infância, ao longo da minha vida, fui compreendendo na prática o engendramento da cegueira como uma construção simbólica e sociocultural. Igualmente, internalizada a dura experiência da infância, fui também envolvendo minhas investigações com a premissa de que a cegueira é uma forma de visão, um modo particular de ser e estar no mundo. Visão esta que se constrói no e com o corpo, em transação com o ambiente, engendrando o que chamei, posteriormente de Mundividência Tátil (Sousa, 2015). 


\section{A cegueira como construção sociossimbólica: internamento e memória}

Eu ia fazer sete anos, quando desvelou-se o dia em que seguiria para a escola especial, junto com meus irmãos mais velhos ${ }^{1}$. Esta é pois a segunda memória mais intensa e persistente dos dias da minha infância. Me recordo que estávamos todos à espera do transporte que nos levaria para a cidade de Itapetim. Meu pai me segurava ao colo, e me perguntou, com lágrimas nos olhos: "Fifia, você ainda é pequena, se quiser ficar, você fica. Me lembro que eu também chorava, mas disse: ‘Não, pai, eu vou!'”.

Aquelas quatro palavras forjaram o primeiro corte, a primeira separação. Quantas crianças cegas iguais a mim já não teriam vivido essa primeira dura experiência de deixar a família? Avalio constantemente essa lembrança e compreendo que, para muitas pessoas cegas, até o final da década dos 70 do século $\mathrm{XX}$, cegueira significava o recolhimento dos corpos, a internação, o disciplinamento para o aprendizado: da convivência com seus iguais; do braile; do ordenamento dos gestos e ações; de toda a gramática simbólica e narrativa envolvida.

E veio o terceiro episódio mais central das minhas memórias da infância: entre os sete e os oito anos, num fim de tarde, eu estava na minha cama, com a cartilha aberta, tentando ler. E de repente meu cérebro fez um clique, minha mão associou letras e formou palavras. Recordo-me do sorriso estufando minhas bochechas, da felicidade, da loucura de ficar lendo e lendo, até não mais poder.

Eu havia me desapropriado dos hábitos de casa, de viver brincando no meio do campo, de falar sozinha, de atritar pedras para sentir o cheiro de fogo. Havia ganhado outros hábitos: uma vida regulada pelo sino, o banho frio às cinco da manhã, as horas de rezar, de brincar e de dormir, compartilhando muitas vezes as roupas e até um espaço na mesma cama com outra menina.

O aprendizado do braile foi uma recompensa e tanto. A literatura me fazia abstrair daquele mundo ordenado, me permitia vagar por lugares onde eu não tinha que me impor limites. Desde então, envolvi-me de tal forma com a literatura, que, às vezes, vivia uma espécie de ilusão: eu habitava o mundo dos livros e era de lá que as vezes visitava o mundo real.

Aprendi a gostar da escola, mas havia os lugares prediletos: os pátios abertos, o pequeno jardim próximo às salas de aula, e, com toda certeza, a biblioteca. Lá eu podia ficar horas a fio, lendo. Mas a hora de que eu mais gostava, era aquela do final de tarde, quando já havíamos tomado banho e aguardávamos a hora do jantar. Eu corria para a biblioteca escura e silenciosa, e ficava lendo, sim, porque ler em braile não exige luz, senão as polpas dos dedos indicadores, correndo pela página aberta, desvendando as aventuras de Pedrinho, de Narizinho e do príncipe escamado².

Até a quarta série do ensino primário, na escola especial, éramos poupados de muitos constrangimentos. Estávamos entre nossos iguais, tínhamos atendidas nossas necessidades, de alimentação, dormida, estudos e brincadeiras. Após a quarta série, porém, vinha uma espécie de ruptura desse mundo protegido. Muitos de nós passávamos a estudar em escolas comuns. Naquela época, porém, era muito mais um experimento que uma ação planejada.

Não existiam salas de recurso, tampouco produção do livro didático adotado na escola onde nos tinham matriculado. Contávamos somente com o serviço de itinerância, para produzir e transcrever nossos exercícios e provas ${ }^{3}$.

Surgiam, pois, os primeiros constrangimentos: se na escola especial tínhamos autonomia, na escola regular, éramos postos de parte. Não líamos na mesma hora que os outros, não participávamos das atividades de desenho e confecção de mapas. Na hora do recreio, não podíamos participar dos jogos de tênis nem do "barra-bandeira"4.

Mais do que nunca, nessa época, penso ter internalizado e vivido os gestos de estar quieta, ouvindo, apreendendo, negando ao meu corpo muitas das travessuras que anteriormente eu experimentara, no sítio e na escola especial.

\footnotetext{
${ }^{1}$ Meus pais tiveram sete filhos cegos e seis filhos com visão normal. Todos os filhos cegos estudamos no Instituto dos Cegos Adalgisa Cunha, em João Pessoa, na Paraíba. Minha permanência na escola especial durou dos sete aos 15 anos (1963-1972).

${ }^{2}$ Referência à obra "Reinações de Narizinho", de Monteiro Lobato.

${ }^{3} \mathrm{O}$ serviço de itinerância é exercido por um professor especializado, que transcreve provas em braille, e faz adaptação de tarefas, para apoiar professores de alunos cegos em escolas comuns.
}

${ }^{4}$ No Nordeste essa brincadeira também é chamada de "academia". 


\section{Quando somente a teimosia lhe leva aonde você quer ir}

Aos 16 anos, já vivendo com minha família, que veio morar em João Pessoa, eu decidi que queria ser jornalista. Àquela época, sequer havia uma faculdade de jornalismo em minha cidade, mas penso que era o solo da literatura que me empurrava para esse desejo. Eu sequer pensava nas consequências e nos óbices, ainda que fosse frequentemente alertada pelos educadores da escola especial: jornalista? Como? Você não conseguirá emprego!

Penso que a teimosia, e mais que isso, a irreflexividade própria da adolescência, me impeliram até a realização do meu desejo.

Passei no vestibular da segunda turma da escola de jornalismo, na Universidade Federal da Paraíba (UFPB), em 1978. Já durante o curso, tive oportunidade de trabalhar como freelancer no jornal semanal "O Momento", no qual ainda produzi quatro grandes reportagens. Formei-me em agosto de 1981, e 15 dias após a formatura, eu era convidada para uma experiência de trabalho, no jornal "O Norte", dos Diários Associados $^{5}$. Ali trabalhei como repórter durante quase nove anos, contrariando as perspectivas sombrias dos técnicos da educação especial. No internato, eles tinham me dado uma ferramenta fundamental para o trabalho no jornal. Tinham me ensinado datilografia. Então, eu era a única jornalista que anotava em braile e, como meus colegas, digitava a matéria na máquina de datilografia.

Na universidade, eu havia formado meu espírito militante. Atuava em várias frentes: no movimento estudantil e, paralelamente, no movimento de pessoas com deficiência. Levei também a militância para o jornalismo. Participei ativamente das duas grandes greves gerais de trabalhadores, entre os anos 1989/1990. As greves fizeram com que o clima nas redações ficasse extremamente hostil para os militantes e sindicalistas. Foi nessa época que decidi deixar a reportagem e retomar os estudos.

Cursei mestrado em ciências sociais e, em 1993, passei em seleção para professor substituto na mesma universidade e no mesmo curso onde havia estudado. Em 1994 veio o veio o concurso efetivo e, desde então, passei a ingressar o quadro dos docentes permanentes da minha faculdade.
O doutoramento em Comunicação e Semiótica deu-se entre os anos de 2000/2004, na Pontifícia Universidade Católica de São Paulo. Atualmente ministro aulas nos cursos da graduação e pós-graduação em Jornalismo, e estou a braços com mais um desafio: a editoria geral de Ancora, Revista Latino Americana de Jornalismo ${ }^{6}$.

Narrar os acontecimentos da minha juventude, até os dias atuais, com a ligeireza da escrita, pode levar os leitores a crerem que toda essa trajetória deu-se de maneira tranquila, sem percalços maiores. No próximo tópico, porém, ao mesmo tempo em que tentarei organizar os eixos disciplinares da minha formação/atuação, inventariarei as dificuldades de acessibilidades atinentes a cada época vivida.

\section{A costura dos tempos: dos eixos de formação ao rol das dificuldades}

Do ponto de vista da história, assim como do desenvolvimento das políticas de atenção à coletividade cega e com deficiência visual, essa minha trajetória está circunscrita a três grandes momentos: o primeiro, caracteriza-se pelo que eu chamei, em trabalho anterior, de o modelo do internamento dos cegos em "instituições totais" (Goffman citado em Belarmino, 1997). O segundo momento demarca o modelo inclusionista, abarcando os anos 1980/1990 e o início do século XXI. Finalmente, a era atual, caracterizada como era tecnológica, na qual vivemos os primeiros esforços mais significativos para a acessibilidade e a inclusão.

Ter experimentado essas três épocas, permite-me reunir vivências que podem ilustrar situações e problemáticas vividas pela coletividade de pessoas cegas, guardando-se as devidas proporções, contextos e particularidades de cada pessoa.

Poderia afirmar, de maneira mais geral, que cada uma dessas épocas demonstrou, ora de maneira mais acentuada, ora de maneira menos significativa, processos de invisibilidade que marcam a trajetória do desenvolvimento da cultura em relação à cegueira. $\mathrm{O}$ modelo de internamento, em certa medida, afastou os indivíduos cegos do convívio com a sociedade, e, por assim dizer, dos processos normais de educação, formação profissional e sociabilidade. Revelava-se nesse período, um binômio catastrófico: o estado

${ }^{5} \mathrm{O}$ jornal "O Norte" foi, por muito tempo, o impresso de maior tiragem na Paraíba. Assolado por inúmeras crises financeiras, o diário fechou em 2012.

${ }^{6}$ Disponível em: http://www.periodicos.ufpb.br/ojs/index.php/ancora. 
demonstrava-se inábil para acolher as pessoas com deficiência em seus modelos socioculturais de desenvolvimento e assim, legava à caridade, sobretudo, a criação de espaços especiais para o atendimento dessas pessoas.

O modelo inclusionista dá um passo à frente, reconhece-se a obrigação do estado para com a educação de todas as pessoas, assim como se estabelece que é o estado e a sociedade que terão de adequar-se para acolher pessoas com deficiências nas suas necessidades e desenvolvimento de competências e habilidades.

O modelo inclusionista vive, pois, sua fase atual, em que se espera que a acessibilidade e a inclusão não sejam mais realizações experimentais, mas antes, políticas de estado instituídas por força de um marco legal competente, e consolidadas nos diversos interstícios da sociedade.

Há um esforço no sentido de se reconhecer a igualdade na diferença, entretanto, persistem, cristalizadas na cultura, marcas da invisibilidade dessas pessoas, seja no que toca ao acesso dos bens culturais, seja no pleno usufruto dos direitos de cidadania.

Antes, porém, de tratar do que chamarei de "novas barreiras para a acessibilidade e a inclusão", quero discorrer sobre os achados reflexivos que a minha trajetória pessoal, associada às pesquisas desenvolvidas, me permitiram formular, e com os quais reflito sobre a cegueira, a percepção tátil e a importância de darmos lugar a tais reflexões.

\section{Pensar a cegueira como uma forma de visão}

Quando observamos o imaginário forjado sobre a cegueira ao longo da história da cultura, nos deparamos, pelo menos até os primórdios do século $\mathrm{XX}$, com um conjunto de compreensões que a tomaram como desgraça, castigo a ser expiado, sobretudo como patologia. Num outro ângulo, operava uma espécie de visão mágica da cegueira, que também colocava seus indivíduos num patamar distante da normalidade.

Tais compreensões reverberaram sobretudo na ciência, que tomou a visão como o sentido mais importante e fundamental para a obtenção de conhecimento e em geral pensou a cegueira como patologia, geradora de incapacidades naqueles que a possuíam.
O avanço das ciências do cérebro, assim como da antropologia, biologia e Psicologia, entre outras, foram aos poucos rompendo com esse modo de pensar, forjando, portanto, compreensões da cegueira como força e como potência.

Seria longo referir aqui, o conjunto dos autores que transformaram fundamentalmente as compreensões das ciências com respeito à cegueira. Vale, entretanto, destacar alguns nomes que têm sido fundamentais para essas transformações?

Maturana (1997) e Varela, Thompson, \& Rosch (2003) refletiram sobre a percepção e a cognição como experiências encarnadas no corpo, além de contribuir com inúmeros outros conceitos e reflexões inspiradoras da construção de um pensamento da cegueira como potência. Sacks $(1989,1995)$ retomou com vigor o imperioso debate de se reconhecer a cegueira, suas particularidades, sua qualidade de ser uma experiência positiva, desde que atendidas as necessidades destes indivíduos, no que toca à educação, ao trabalho, à cultura.

Gardner (1994) colaborou para uma compreensão de competentes processos cognitivos que podem ser desempenhados por crianças cegas, desbancando uma visão incapacitante da cegueira predominante nas ciências clássicas.

Um alentado e recente estudo de referência sobre a cegueira realizado no Brasil é a tese de doutorado de Olivia Von Der Weid "Visual é só um dos Suportes do Sonho, Práticas e Conhecimentos de Vidas com Cegueira". Defendida em 2014, reflete e dialoga com um conjunto vasto de teorias e modelos, passando pelo modelo patológico, até o chamado modelo funcional. Mais que isso, a tese ilumina os debates sobre percepção, corporalidade, práticas de normalização da educação especial, entre muitos outros temas caros aos estudos da cegueira.

Pensar a cegueira como uma forma de visão é uma premissa, se quisermos uma metáfora que aparece também nos meus estudos, mas posso dizer que essa compreensão foi aos poucos engendrando-se no amálgama das minhas experiências pessoais em conjugação com as múltiplas leituras que fui fazendo ao longo da minha formação intelectual. A primitiva experiência com as pedras, o aprendizado do braille,

\footnotetext{
${ }^{7}$ Importante trabalho, nos últimos 20 anos, levado a cabo pelo Núcleo de pesquisa Cognição e Coletivos, do Programa de Pós-graduação em Psicologia da Universidade Federal do Rio de Janeiro (UFRJ), tem recuperado e atualizado inúmeras pesquisas e reflexões sobre a cegueira, inspiradas na maior parte desses e de outros contributos teóricos que pensam a cegueira como diferença e como potência.
} 
são, por assim dizer, as matrizes fundadoras da ideia bruta, que depois converteu-se em conhecimento.

Pensar a cegueira como uma forma de visão exige que se reconheça, na ciência, na sociedade, na cultura, um modo particular de ser e estar no mundo, que não é "desgraça" nem patologia, mas, antes, um modo de ser e de estar no mundo que produz conhecimento e colabora com o conhecimento global constituído.

No doutorado, para precisar melhor essa compreensão, inspirada na concepção advinda da biologia de Jacob Von Uexküll (1899/1940), cunhei a expressão "mundividência tátil" para falar da experiência da cegueira, mais particularmente dos fenômenos da percepção e cognição, crucialmente dependentes do complexo tátil (Sousa, 2015).

A primitiva lição das pedras, sem que eu percebesse na época, tinha me posto em contato com os processos cinestésicos que envolvem o corpo de uma pessoa cega em transação com o ambiente; a leitura e escrita braille, para além dessa ferramenta, é um profundo e competente dialogo entre mão e cérebro de uma criança cega, refazendo sinapses e conexões, habilitando funções cerebrais, consolidando um gesto fundador do lugar da pessoa cega como intelectual na cultura da escrita.

Essa breve explanação do percurso teórico, com lacunas irreparáveis, permite-nos olhar para o avanço do pensamento científico sobre a cegueira. Mas, nos leva a reconhecer que persistem, na cultura, no planejamento e na aplicação de políticas de atendimento, ou na falta destas, os fantasmas de uma visão de mundo patológica, desvantajosa, ignorando ou invisibilizando a cegueira e a mundividência tátil, reforçando preconceitos e discriminações danosos ao desenvolvimento pleno da pessoa humana.

\section{A infovia cibernética: um novo lugar de estranhamento da cegueira}

O desenvolvimento da trajetória das pessoas cegas pode ser avaliado levando-se em conta o próprio desenvolvimento da comunicação, no qual estão demarcadas três grandes eras: a da oralidade, quando as pessoas cegas somente podiam expressar-se via comunicação oral (milhares e milhares de anos, até o fim da segunda década do século XIX); A era do relevo (século XIX até a atualidade); a era da sociedade informática (contemporânea e que pode fazer declinar o uso do braille).
Nessas três épocas, em maior ou menor medida, a sociedade, pode-se dizer, operou com uma espécie de incapacidade de conviver com a cegueira. Na literatura, no cinema, esse imaginário forjou, para personagens cegos, finais felizes em que lhes era dado recuperar a visão. A era tecnológica saiu do romantismo, para vender soluções ora de substitutos da visão, se quisermos, suportes tecnológicos para uma "visão mediada”. Nos limites desse artigo, não há como aprofundar a exploração dessa ideia, senão remetê-la a pesquisas e análises futuras.

Aqui importa reconhecer que a tecnologia, por excelência, trouxe respostas reabilitadoras de muitas das limitações impostas pela cegueira, ou pela falta de condições de acesso da própria sociedade. Estratégias de acessibilidade implementadas nos computadores, e, mais recentemente, nas tecnologias móveis, propiciam que pessoas cegas possam transitar nos ambientes virtuais com a mesma desenvoltura daqueles que enxergam.

Há que se reconhecer, entretanto, que muitos dos agentes da era informática desconhecem ou desconsideram a presença das coletividades cegas e com deficiência visual no ciberespaço.

Tal como nas vias públicas e praças das cidades, nos museus e teatros, nos espaços públicos e privados para bens e serviços, na infovia cibernética, todos os dias, são forjadas barreiras virtuais de acessibilidade.

Os cidadãos cegos de hoje, tal como ocorria nas épocas anteriores, inventam suas táticas de permanência no ciberespaço, mas, quando progridem conquistando acesso, barreiras novas são forjadas.

Conforme argumentei em outro trabalho (Souza, \& Siqueira, 2017):

O ciberespaço pode se configurar em um território que invisibiliza inúmeras comunidades, quando não implementa legendas textuais para conteúdos imagéticos, ou quando a maioria dos seus desenvolvedores desconhece as normas internacionais de acessibilidade na web. Paradoxalmente, é na ciberesfera onde as pessoas com deficiência podem ser vistas, graças aos processos de hipertextualidade e de hashteguização envolvidos. Esse é, porém, um território ainda difuso, onde os pontos de encontro, de conexão e de comunicação são frutos do improviso, do acaso, da interação espontânea e do número de curtidas (p. 127). 
No início do artigo, lancei uma questão primordial: a de que a cegueira é um lugar de onde se parte para olhar o mundo. Agora podemos contemplar a contraface dessa questão: Como o mundo olha para a cegueira?

\section{Considerações finais}

Esse texto tentou juntar experiência pessoal $\mathrm{e}$ formação intelectual para, a partir da minha fala, aflorar alguns dos diversos temas que envolvem a cegueira e o debate sobre esta condição. Temos ciência da fragilidade da narrativa, no sentido de fazer cumprir a necessidade do aprofundamento das questões aqui abordadas. Temos ciência, porém, do inacabado, da incompletude, que sempre presidem a tarefa intelectual de pensar, tendo como única armadura a memória e as palavras.

A academia está povoada por esse esforço intelectual de descrever e explicar a cegueira e suas trajetórias, particulares ou coletivas. Minha trajetória com a cegueira me ensina todos os dias. Minha trajetória com a cegueira justifica, todos os dias, a ideia da força e da potência, assim como me mostra os fracassos e os sucessos da sociedade no sentido de humanizar a convivência com pessoas cegas.

Assim, tentando explorar a última questão proposta, digo que o mundo atual olha para a cegueira com espelhos diversos e que muitos desses espelhos estão atravessados pelos antigos fantasmas da patologia, do preconceito, da indiferença.

A visão mediada, servida por dispositivos tecnológicos, é o novo patamar que se apresenta, seja para reali- zar o milagre inventado pela literatura e pela telenovela, seja para criar novos lugares de discriminação, visto que a maior parte desses dispositivos milagrosos têm preços proibitivos para a maior parte das pessoas cegas, advindas das camadas mais pobres da sociedade.

Ao tempo em que concluo esse artigo, provavelmente, em muitos lugares do mundo, estão sendo gestadas soluções tecnológicas hipercaras, que propiciam que uma pessoa cega leia textos impressos, reconheça rostos, possa tocar em elementos intangíveis, como uma imagem vinda do espaço. As gigantes tecnológicas do mundo, como Microsoft, Google e Apple trabalham febrilmente para que pessoas cegas possam reconhecer, via dispositivos e/ou aplicativos tecnológicos, a grande avalanche de imagens que povoa a sociedade atual.

Tal como ocorria nas sociedades antigas, nas quais somente os cegos afortunados eram vistos, as conquistas tecnológicas da sociedade contemporânea só chegam a uns poucos afortunados.

Ao longo da sua trajetória milenar, a cegueira inventou modos de ser vista. Fosse cantando nas feiras públicas, fosse escrevendo em braille, fosse engrossando as lutas políticas por melhores dias para todos. Em todos os tempos, cegos rejeitaram um lugar ora privilegiado, ora desvantajoso, ora quase divino, ora quase invisível. Em todos os tempos, cegos quiseram ser vistos como eles são, pessoas que tocam nas palavras para forjar sua leitura de mundo.

Tal como nas sociedades antigas, esse é também um desafio a ser cumprido na sua plenitude na sociedade contemporânea.

\section{Referências}

Belarmino, J. (1997). Associativismo e política: A luta dos grupos estigmatizados pela cidadania plena. João Pessoa, PB: Idéia.

Gardner, H. (1994). Estruturas da mente: A teoria das inteligências múltiplas. Porto Alegre, RS: Artes Médicas.

Kastrup, V. \& L. Pozzana, L. (Orgs.). Histórias de cegueiras. Curitiba, PR: CRV.

Maturana, H. (1997). A ontologia da realidade. Belo Horizonte, MG: Editora da UFMG.

Sacks, O. (1995). Um antropólogo em Marte: Sete histórias paradoxais. São Paulo, SP: Companhia das Letras.

Sacks, O. (1998). Vendo vozes. São Paulo, SP: Companhia das Letras.

Sousa, J. B. (2000). O que vê a Cegueira. Revista Benjamin Constant, 16, 1-3. Recuperado de http:/ /www.ibc.gov.br/images/conteudo/revistas/benjamin_constant/2000/edicao-16-agosto/Nossos_Meios_RBC_RevAgo2000_RELATO.pdf

Sousa, J. B. (2015). O que vê a cegueira: A escrita Braille e sua natureza semiótica. João Pessoa, PB: Editora da UFPB.

Sousa, J. B., \& Siqueira, J. M. (2017). Redes sociais: Tecnologias assistivas para a inclusão e a cidadania. Periferia: Educação, Cultura e Comunicação, 9(2), 112-129. https://doi.org/10.12957/periferia.2017.28996 
Varela, F., Thompson, E., \& Rosch, E. (2003). A mente incorporada: ciências cognitivas e experiência humana. Porto Alegre, RS: Artmed.

Von Der Weid, O. (2014). Visual é só um dos suportes io de do sonho (Tese não publicada). Universidade Federal do Rio de Janeiro, RJ.

Joana Belarmino de Souza

Professora associada do curso de Jornalismo da Universidade Federal da Paraíba (UFPB), João Pessoa - PB. Brasil. E-mail: joanabelarmino00@gmail.com

Endereço para envio de correspondência:

Joana Belarmino de Sousa

Rua Deputado Geraldo Mariz, 525, ap. 704, Bairro Tambauzinho. CEP: 58042-060.

João Pessoa - PB. Brasil.

Recebido: $11 / 07 / 2018$

Aprovado: 07/08/2018

Received: 07/11/2018

Approved: 08/07/2018

Recibido: $11 / 07 / 2018$

Aceptado: 07/08/2018

Como citar: de Souza, J. B. (2018). Cegueira, Acessibilidade e Inclusão: Apontamentos de uma Trajetória. Psicologia: Ciência e Profissão, 38(3), 564-571. https://doi.org/10.1590/1982-3703000092018

How to cite: de Souza, J. B. (2018). Blindness, Accessibility and Inclusion: A Trajectory. Psicologia: Ciência e Profissão, 38(3), 564-571. https:// doi.org/10.1590/ 1982-3703000092018

Cómo citar: de Souza, J. B. (2018). Ceguera, Accesibilidad e Inclusión: Una Trayectoria. Psicologia: Ciência e Profissão, 38(3), 564-571. https:// doi.org/10.1590/1982-3703000092018 